\title{
Antioxidant Activity of Allium hookeri Root Extract and Its Effect on Lipid Stability of Sulfur-fed Pork Patties
}

\author{
Han-Seul Cho, Woojoon Park, Go-Eun Hong, Ji-Han Kim, Min-Gu Ju, and Chi-Ho Lee* \\ Department of Food Science and Biotechnology of Animal Resources, Konkuk University, Seoul 143-701, Korea
}

\begin{abstract}
This study was performed to assess the antioxidant activity of Allium hookeri root extract (AHE) on lipid oxidation of raw sulfur-fed pork patties for $14 \mathrm{~d}$ of refrigerated storage. Different concentration of ethanol $(0-100 \%)$ and time (1-12 h) were applied to determine the extraction condition. Water $(0 \%$ ethanol $)$ extraction for $1 \mathrm{~h}$ was selected as an optimal extraction condition of AHE for the following study showing the highest total phenolic content and total flavonoid content, as well as the strongest antioxidant activity. The 1\% AHE (SP1), 3\% AHE (SP2), and $0.05 \%$ ascorbic acid (SP3) were added into sulfur-fed pork patties against controls; SP0 (sulfur-fed pork patties with no AHE) and P0 (normal pork patties with no AHE). The $\mathrm{pH}$ values of P0 and SP0 significantly increased $(p<0.05)$ than others on $14 \mathrm{~d}$ and redness of P0 showed the largest decrement during storage. P0 and SP0 showed higher production of conjugated dienes on $\mathrm{d} 7$ than others $(p<0.05)$. Thiobarbituric acid reactive substances (TBARS) values were decreased in proportion to the increased level of AHE on $14 \mathrm{~d}(p<$ $0.05)$ resulting in higher TBARS values on P0 and SP0 $(p<0.05)$ and the negative correlation between AHE level and TBARS were also demonstrated $(\mathrm{r}=-0.910, p=0.001)$. Therefore, the results suggest that AHE effectively retarded the lipid oxidation rate of sulfur-fed pork patties indicating the potential usage of AHE as a natural preservative.
\end{abstract}

Key words: allium hookeri, antioxidant activity, sulfur-fed pig, pork patty, lipid oxidation

\section{Introduction}

In muscle product lipid oxidation is mainly responsible for deterioration of quality during storage, and it can cause unpleasant tastes, off-flavors, color changes, and rheological property changes (Juntachote et al., 2006). These oxidative reactions also can diminish the nutritional quality of product, and form toxic compounds (Thongtan et al., 2005). Especially, ground meat is highly susceptible meat products on lipid oxidation and putrefaction during processing, and storage, since grinding procedure provokes increment of meat surface area exposed to air, loss of intracellular reductants, and contamination by microorganisms (Park and Chin, 2010; Sánchez-Escalante et al., 2001).

Many efforts have been made to decrease those issues and increase the shelf life of meat products such as production of higher quality of meat, and addition of antioxidants. Recently, sulfur has been fed in pigs, and ducks to

\footnotetext{
*Corresponding author: Chi-Ho Lee, Department of Food Science and Biotechnology of Animal Resources, Konkuk University, Seoul 143-701, Korea. Tel: +82-2-450-3681, Fax: +822-453-1948, E-mail: leech@konkuk.ac.kr
}

produce meat of quality. Sulfur, which is an inorganic element, is one of the major metabolic nutrients, and biologically essential because of its cooperation with amino acids, proteins, enzymes, vitamins and other components (Atmaca, 2004). Sulfur compounds are also known to have antioxidant, anti-inflammatory, antimicrobial, and anticancer activities (Battin and Brumaghim, 2009). However, sulfur itself has toxicity to human when taken directly, hence it should be used after attenuation process or in a natural form of methylsulfonylmethane (Choi and Kim, 2002; Kim et al., 2006). Lee et al. (2009) reported that sulfur-fed pigs showed low lipid oxidation rate and higher sulfur content than non-sulfur-fed pigs.

Addition of synthetic antioxidants, including butylated hydroxyanisole (BHA) and butylated hydroxytoluene (BHT) also decreases lipid oxidation rate (Ryu et al., 2014). However, those compounds may cause health risks. Several studies have shown that BHA is a potential lesion formation in the rat forestomach, and BHT may occur internal and external haemorrhagie when used at high doses which is enough to lead to death in some strains of mice and guinea pigs (McCarthy et al., 2001).

Therefore instead of synthetic antioxidants, natural antioxidants attract great attention because of their safety. 
Several studies have been reported that natural resources such as vegetables, herbs, and fruits are excellent antioxidants (Kanatt et al., 2007; Leong and Shui, 2002). Many protective constituents derived from those plant materials, including selenium and other mineral micronutrients, carotenoids, phytoestrogens, glucosinolates and indoles, dithiolthiones, isothiocyanates, protease inhibitors, fibre, folic acid, and phenolic compounds are important attributors on their remarkable radical scavenging activity (Rice-Evans et al., 1997). Many natural antioxidants have been reported on their positive effects on the lipid oxidation inhibition in meat products, for example, tea leaf extract (Jo et al., 2003) and white grape extract (Jonberg et al., 2011).

Allium species contain an abundance of organo-sulfur compounds, volatile sulfur compounds, proteins, prostaglandins, fructan, vitamins, and polyphenols, and particularly, its sulfur and numerous phenolic compounds make them great of interest (Dziri et al., 2012). Allium hookeri which is a member of family Alliaceae subgenus Amerallium, is found in Ceylon, Greece, Yunnan, Southern China, Bhutan, Sri Lank, and India. These plants have been used by the locals to treat cough and cold, and heal burns and wounds (Sharma et al., 2011).

Several studies have demonstrated antioxidant activity and anti-inflammatory effect of Allium hookeri (Bae et al., 2012; Kim et al., 2012; Won et al., 2013), however, there is still insufficient information available on many factors such as extraction condition, its influences on contents of antioxidant compounds, and application in the meat product. Thus, this study was conducted to optimize extraction condition of Allium hookeri root and determine the lipid oxidation inhibitory effect of Allium hookeri root extract on raw sulfur-fed pig patties during storage to obtain a possibility as a natural preservative replacement.

\section{Materials and Methods}

\section{Materials and chemical}

Commercial Allium hookeri roots were purchased from Samchaenara Co. (Korea) and freeze dried at Dongil Cold Storage \& Foods Co. (Korea). Pork loin, processed sulfur-fed pork loin, and pork backfat were purchased to prepare pork patties from a local slaughterhouse in Seoul, Korea. Chemicals including Folin-Ciocalteu's phenol reagent, sodium carbonate, aluminium chloride, quercetin, 2.2-dipnenyl1-1-picrylhydrazyl (DPPH), 2,2-azino-bis (3ethylbenzothiazoline-6-sulfonic acid) diammonium salt (ABTS), trichloroacetic acid (TCA), 2-thiobarbiuric acid
(TBA), and 1,1,3,3-tetraethoxypropane (TEP) were purchased from Sigma (Sigma-Aldrich, USA). Other chemicals including potassium persulfate and gallic acid were purchased from Samchun (Samchun pure chemical Co., Ltd., Korea) and Kanto (Kanto chemical Co., Inc., Japan), respectively.

\section{Preparation of Allium hookeri root extract (AHE)}

Freeze dried Allium hookeri roots were ground using a blender (HM-310, Hanil Electric, Korea). A $2 \mathrm{~g}$ of Allium hookeri root powder was taken into $100 \mathrm{~mL}$ of different concentration of ethanol $(0,20,40,60,80$, or $100 \%)$ at room temperature and extracted with different extraction time $(1,2,4,8$, or $12 \mathrm{~h})$ in a shaker, respectively. The extracts were filtered through Whatman filter paper (No. 2) and used for total phenolic content, total flavonoid content, DPPH, and ABTS radical scavenging activity determination to assess optimal extraction condition.

As AHE extracted with $0 \%$ ethanol (pure water) for $1 \mathrm{~h}$ showed higher antioxidant activity than other groups, it was used for further study to measure its inhibitory effect on lipid oxidation in raw pork patties. This filtered extract was then evaporated with a rotary evaporator (EYELA N1000 , Rikakikai, Japan) at $40^{\circ} \mathrm{C}$ and was reconstituted into extraction solvent.

\section{Determination of total phenolic and total flavonoid contents}

Total phenolic content of AHE was measured using Folin-Ciocalteu method described by Singleton et al. (1999) with minor modifications. Briefly, $0.5 \mathrm{~mL}$ of AHE was reacted with $2.5 \mathrm{~mL}$ of $0.2 \mathrm{~N}$ Folin-Ciocalteu's phenol reagent for $5 \mathrm{~min}$ at room temperature. This mixture was mixed with $2 \mathrm{~mL}$ of $7.5 \%(\mathrm{w} / \mathrm{v})$ sodium carbonate for $2 \mathrm{~h}$ at room temperature and the absorbance was read at $760 \mathrm{~nm}$ with a spectrophotometer (Optizen 2120UV, Mecasys Co., Ltd., Korea). Total phenolic content was calculated using a standard curve of gallic acid (0-200 $\mathrm{mg} / \mathrm{L}$ ) and was expressed as $\mathrm{mg}$ of gallic acid equivalents (GAE) per gram dry material.

For determination of total flavonoid content, the Dowd method was used described by Meda et al. (2005) with minor discrimination. Briefly, $1.5 \mathrm{~mL}$ of AHE was reacted with $2 \%(\mathrm{w} / \mathrm{v})$ aluminium chloride for $10 \mathrm{~min}$ at room temperature and the absorbance was read at $415 \mathrm{~nm}$. Total flavonoid content was determined by a standard curve of quercetin $(0-50 \mathrm{mg} / \mathrm{L})$ and was expressed as $\mathrm{mg}$ of quercetin equivalents $(\mathrm{QE})$ per gram dry material. 


\section{Determination of DPPH and ABTS scavenging activity}

The DPPH scavenging activity of AHE was evaluated according to Mensor et al. (2001) with minor modifications. A $1.25 \mathrm{~mL}$ of each AHE extract with different extracting conditions and $0.5 \mathrm{~mL}$ of $0.3 \mathrm{mM}$ DPPH solution dissolved in $95 \%$ ethanol were mixed thoroughly and after incubated in the dark for $30 \mathrm{~min}$, the absorbance was read at $518 \mathrm{~nm}$.

The ABTS scavenging activity was determined by the method described by Re et al. (1999) with minor modifications. Briefly, $7 \mathrm{mM}$ ABTS stock solution was mixed with $2.45 \mathrm{mM}$ potassium persulfate (final concentration) and incubated for $12 \mathrm{~h}$ in the dark at the room temperature to prepare $\mathrm{ABTS}^{\cdot+}$ working solution. This working solution was diluted with phosphate-buffered saline $(\mathrm{pH}$ 7.4) to obtain an absorbance of $0.7 \pm 0.02$ at $732 \mathrm{~nm}$. A 1.8 $\mathrm{mL}$ of diluted working solution and $0.2 \mathrm{~mL}$ of test sample were mixed, incubated for a minute, and finally the absorbance was read at $732 \mathrm{~nm}$.

The DPPH and ABTS scavenging activity values were calculated as follows:

DPPH or ABTS scavenging activity $(\%)=\left[\left(\mathrm{A}_{0}-\mathrm{A}_{1}\right) /\right.$ $\left.\mathrm{A}_{0}\right] \times 100$

$\mathrm{A}_{0}$ was the absorbance of the control which was DPPH or $\mathrm{ABTS}^{*+}$ solution with extracting solution only and $\mathrm{A}_{1}$ was the absorbance of each sample.

\section{Preparation of pork patties}

The excessive fat and connective tissue of pork loin (P) and sulfur-fed pork loin (SP) were removed from the meat. $\mathrm{P}$ and SP meat were ground through $5 \mathrm{~mm}$ plates respectively with $20 \%$ pork backfat. Ground SP (20\% fat) mixed with $20 \mathrm{~g} / \mathrm{kg} \mathrm{NaCl}$ divided into 4 portions for different AHE treatment, including control (SP0, no AHE), 1\% AHE (SP1), 3\% AHE (SP2), 0.05\% ascorbic acid with no AHE (SP3). Ground P (20\% fat) mixed with 20 $\mathrm{g} / \mathrm{kg} \mathrm{NaCl}$ was used as a control (P0) against to SP0. Each mixture portion with different treatment was mixed and formed into patties (1,001 g each) using $1590 \mathrm{~mm}$ sterilized petri dishes. Patties were than packaged using a linear low-density polyethylene film and stored in a refrigerator at $4^{\circ} \mathrm{C}$ for $14 \mathrm{~d}$. For each treatment, 20 patties were prepared and for each storage period, 5 patties were used for experiments.

\section{pH}

A $2 \mathrm{~g}$ of each patty was taken with $18 \mathrm{~mL}$ of distilled water and homogenized for $1 \mathrm{~min}$. The $\mathrm{pH}$ values of patties were measured using a pH meter ( $\mathrm{pH}$ 900, Precisa Co, UK).

\section{Color}

Changes in surface color of raw pork patties during storage were measured using a colorimeter (Chroma meter CR-400, Konica Minolta Optics, Inc., Japan). The color was expressed with CIE L* (lightness), a* (redness), and $b^{*}$ (yellowness) color values.

\section{Conjugated dienes (CD)}

Determination of $\mathrm{CD}$ concentration was performed by the method of Peña-Ramos and Xiong (2003) with minor modifications. Briefly, $0.5 \mathrm{~g}$ of each sample was homogenized with $5 \mathrm{~mL}$ of distilled water and $0.5 \mathrm{~mL}$ aliquot of each suspension was mixed with $5 \mathrm{~mL}$ of hexane/isopropanol $(3: 2, \mathrm{v} / \mathrm{v})$ for $1 \mathrm{~min}$. Mixtures were centrifugated at 2,000 $\mathrm{g}$ for $5 \mathrm{~min}$ and the supernatants were read at 233 $\mathrm{nm}$. Concentration of CD was calculated with the molar extinction coefficient of $25,500 \mathrm{M}^{-1} \mathrm{~cm}^{-1}$ and the result was expressed as iM per mg sample.

\section{Thiobabrituric acid reactive substances (TBARS) values}

Lipid oxidation of raw patties was evaluated by the method according to Witte et al. (1970). In brief, $10 \mathrm{~g}$ of sample was homogenized with $50 \mathrm{~mL}$ of $10 \%(\mathrm{w} / \mathrm{v}) \mathrm{TCA}$ for $1 \mathrm{~min}$ and this mixture was adjusted to $50 \mathrm{~mL}$ with distilled water. The dispersion was filtered and after $5 \mathrm{~mL}$ of the filtrate was mixed with $5 \mathrm{~mL}$ of TBA $(2.88 \mathrm{~g} / \mathrm{L}$ $\mathrm{H}_{2} \mathrm{O}$ ), it was heated in a boiling water bath for $10 \mathrm{~min}$ to develop the rose-pink color. After cooling down the mixture to room temperature, the absorbance was read at 532 nm. TBARS values were calculated using a standard curve (8-50 nM) of malondialdehyde (MDA) prepared by acidification of TEP. The TBARS value was expressed as mg of MDA per $\mathrm{kg}$ test sample.

\section{Statistical analysis}

All experiments were conducted in triplicate and values were analysed by analysis of variance (ANOVA) using PASW Statistics 18 (PASW 18, SPSS Inc., USA) formerly known as SPSS. Means were compared using Tukey procedure at a significance level of $p<0.05$.

\section{Results and Discussion}

Total phenolic and total flavonoid contents of AHE Total phenolic and total flavonoid contents were mea- 
A

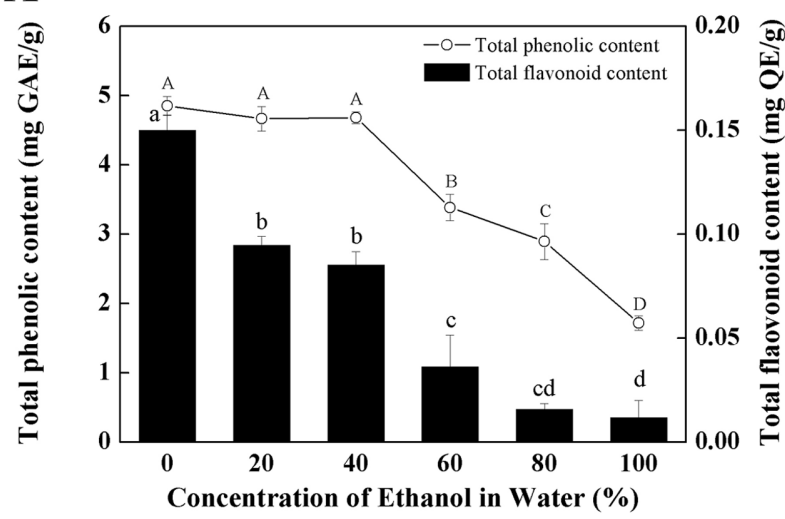

B

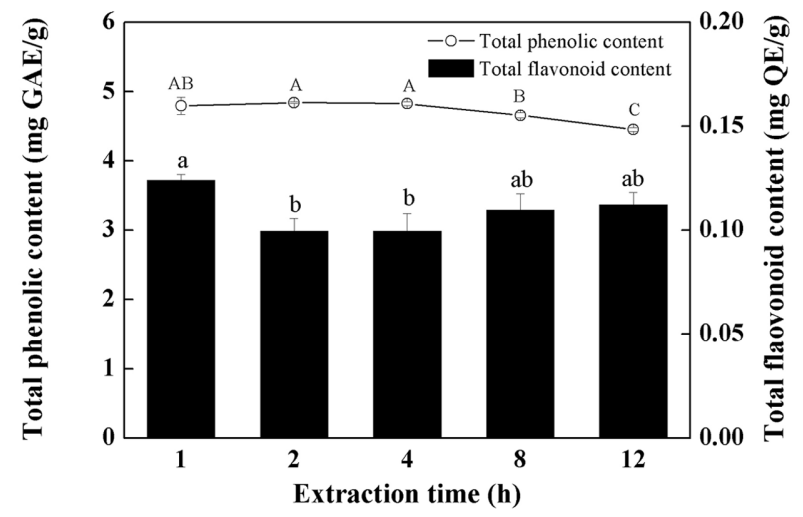

Fig. 1. Total phenolic content and total flavonoid content of Allium hookeri root extract (AHE) depending on (A) concentration of ethanol in water (\%) and (B) extraction time (water extracted). Values are expressed as mean \pm SD of three replicates. ${ }^{\mathrm{A}-\mathrm{D}}$ Means with different letters are significantly different $(p<0.05) .{ }^{\text {a-d }}$ Means with different letters are significantly different $(p<0.05)$.

sured as an attempt to investigate the relationship between different antioxidant activities of AHE. As shown in Fig. 1A, total phenolic and total flavonoid contents decreased as concentration of ethanol was increased. The lowest total phenolic and total flavonoid contents were $1.72 \pm 0.105 \mathrm{mg} \mathrm{GAE} / \mathrm{g}$ and $0.01 \pm 0.008 \mathrm{mg} \mathrm{QE} / \mathrm{g}$, respectively, when pure ethanol was used for extraction. The highest total phenolic content was observed when extracted with pure water $(4.85 \pm 0.135 \mathrm{mg} \mathrm{GAE} / \mathrm{g})$, however no significant difference was observed with $20 \%$ and $40 \%$ ethanol extracts $(p>0.05)$. The highest total flavonoid content was measured when extracted with pure water $(0.15 \pm 0.007 \mathrm{mg} \mathrm{QE} / \mathrm{g})$ which was significantly different $(p<0.05)$.

The influence of extraction time on total phenolic and total flavonoid contents of AHE is shown in Fig. 1B.
Total phenolic content slightly increased until $2 \mathrm{~h}$ of extraction time, but no significant difference $(p>0.05)$ was observed, and total flavonoid content showed the highest value $(0.12 \pm 0.003 \mathrm{mg} \mathrm{QE} / \mathrm{g})$ with $1 \mathrm{~h}$ extraction $(p<0.05)$.

In this study, AHE with pure water for $1 \mathrm{~h}$ extraction was the efficient extraction condition then others on the aspect of total phenolic and total flavonoid contents. In addition, it was noteworthy that the total phenolic content of water extracted AHE was higher than that of garlic (Allium sativum) extract $(1455.9 \mathrm{mg} / 100 \mathrm{~g})$ which was reported by Kaur and Kapoor (2002).

\section{DPPH and ABTS scavenging activity of AHE}

Extraction efficacy of AHE determined by the method of DPPH and ABTS is shown in Fig. 2. Increment of ethanol concentration negatively influenced the DPPH and
A

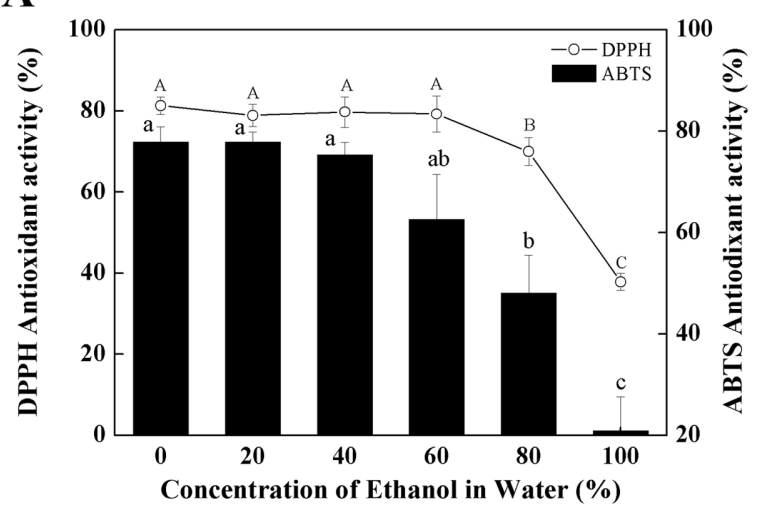

B

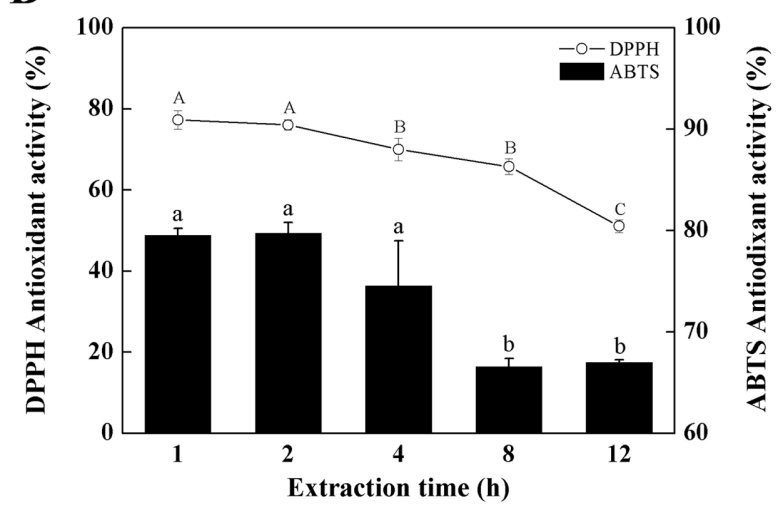

Fig. 2. DPPH and ABTS antioxidant activity of Allium hookeri root extract (AHE) depending on (A) concentration of ethanol in water (\%) and (B) extraction time (water extracted). Values are expressed as mean \pm SD of three replicates. ${ }^{\mathrm{A}-\mathrm{C}}$ Means with different letters are significantly different $(p<0.05) .{ }^{\mathrm{a}-\mathrm{c}}$ Means with different letters are significantly different $(p<0.05)$. 
ABTS antioxidant activity (Fig. 2A). From the DPPH method, radical scavenging activity of AHE was similar up to $60 \%$ ethanol extraction, however it started to decrease significantly $(p<0.05)$ with $80 \%$ and $100 \%$ ethanol extraction. ABTS showed similar profile with decreased antioxidant activity values after $60 \%$ ethanol extraction $(p<0.05)$. Both values of DPPH and ABTS were approximately $80 \%$ when extracted up to $40 \%$ ethanol with no significant difference $(p>0.05)$. Thus, the overall results of total phenolic content, total flavonoid content, DPPH, and ABTS antioxidant activity suggested that pure water was the optimal extraction solvent with a safety benefit in the food industry. In addition, there are several studies on antioxidant activity evaluation and antioxidant components identification of water soluble fraction of Allium species. Wu et al. (2004) compared lipophilic and hydrophilic antioxidant capacities of over 100 different kinds of foods including Allium species such as garlic and onion and reported that garlic powder, onion powder, yellow onion (Cooked and raw both), raw sweet onion, and raw red onion all showed higher hydrophilic antioxidant capacities than lipophilic antioxidant capacities. This high radical scavenging activity may be due to water-soluble antioxidant compounds. Roy et al. (2007) stated phenolic compounds in Alliums such as quercetin 4'-O- $\beta$-glucoside, quercetin 3,4'-O- $\beta$-diglucosides are considered to contribute to their health-promoting properties. Demirtas et al. (2013) also isolated flavons (chrysoeriol-7-O-[2"-OE-feruloyl]- $\beta$-D-glucoside, chrysoeriol, and isorhamnetin3-b-D-glucoside) from water-soluble fraction of Allium vineale and reported their significant antioxidant activity. From those studies, higher antioxidant activity of water extracted AHE than ethanol-water mixture extract AHE may due to such phenolic compounds and flavonoids.

Water extracts differed by extraction time (1-12 h) also influenced the DPPH and ABTS radical scavenging activity (Fig. 2B). More than $2 \mathrm{~h}$ of extraction negatively affected the DPPH and ABTS antioxidant activity. Although, 1 and $2 \mathrm{~h}$ extracts showed similar DPPH, ABTS antioxidant activity, and total phenolic content ( $p>0.05), 1$ $\mathrm{h}$ extract was selected because of its higher total flavonoid content with the benefit of saving time.

Solvent extraction has been widely used to recover antioxidant substances such as phenolic compounds from plant materials, and different solvents (ethanol, methanol, and ethyl acetate etc.) are selected depending on their chemistry characteristics and polarities of target materials from plant materials (Naczk and Shahidi, 2006; Sultana et al., 2009). In addition, different composition of various

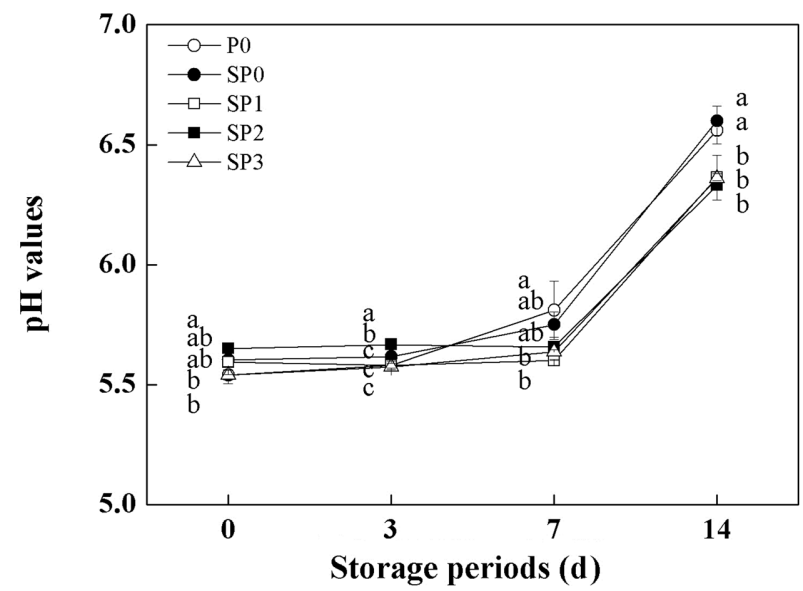

Fig. 3. Effects of Allium hookeri root extract (AHE) on pH values of raw sulfur-fed pork patties, and $\mathrm{pH}$ values of raw normal pork patties during $14 \mathrm{~d}$ of storage at $4^{\circ} \mathrm{C}$. Values are expressed as mean $\pm \mathrm{SD}$ of three replicates. P0, normal pork patties; SP0, sulfur-fed pork patties; SP1, sulfur-fed pork patties with $1 \%$ Allium hookeri root extract; SP2, sulfur-fed pork patties with 3\% Allium hookeri root extract; SP3, sulfur-fed pork patties with $0.05 \%$ ascorbic acid. ${ }^{\mathrm{a}-\mathrm{c}}$ Means with different letters on the same storage day are significantly different $(p<0.05)$.

antioxidants makes harder to find a proper extraction solvent, however, mixtures of ethanol and water with various ratios were used in the present study due to the potential application in the food industry. Thus, water extraction for $1 \mathrm{~h}$ was used as an optimal condition for the following study of sulfur-fed pork patties.

\section{AHE effects on $\mathbf{p H}$ of pork patty}

The $\mathrm{pH}$ changes during refrigerated storage in patties are shown in Fig. 3. The pH values showed increment tendencies in all treatment groups ranging from the lowest value at 5.54 to the highest value at 6.60 during storage period. The $\mathrm{pH}$ increased slightly between the storage $\mathrm{d}$ of 0 and 7, but dramatic rise of $\mathrm{pH}$ value was observed between storage $d$ of 7 and 14. On d 14, AHE and ascorbic acid treated groups showed significantly lower $\mathrm{pH}$ values than P0 and SP0. Park and Chin (2010) reported the similar increment tendency of the $\mathrm{pH}$ value in pork patties treated with onion (Allium cepa) extract during chilled storage. According to Ellis and Goodacre (2001), increased $\mathrm{pH}$ may due to proteolytic activities of microorganisms and its by-products including ammonia, sulphides, indole, scatole, and amines. Therefore, it may indicate that the meat could be spoiled and this explanation is also in accordance with the report of HernándezJover et al. (1996) who observed increased $\mathrm{pH}$ in pork 
meat during storage due to the accumulation of biogenic amines. Hence the lower $\mathrm{pH}$ values of AHE treated groups (SP1 and SP2) than that of non-AHE treated groups may be due to the antimicrobial activity of AHE which was mentioned by Ayam (2011) and Kyung (2012) also stated about antimicrobial components of Allium species such as thiosulfinates, $\operatorname{dialk(en)yl~sulphides,~}$ ajoene, heterocyclic sulfur compounds, allyl alcohol, and 3-(allyltrisulfanyl)-2-aminopropanoic.

\section{AHE effects on color of pork patty}

Changes in $\mathrm{L}^{*}$-, $\mathrm{a}^{*}$, and $\mathrm{b}^{*}$-values of pork patties are presented in Table 1 . There were no significant differences in lightness ( $L^{*}$-value) among all groups on the initial d of measurement $(p>0.05)$. Storage time also did not affect the lightness $(p>0.05)$. Redness $\left(a^{*}\right.$-value) of the AHE treated groups were significantly $(p<0.05)$ lower compared to non-treated groups, showing higher AHE concentration lowered the redness due to the yellowish brown color of AHE. Redness decreased until 3-7 d of storage in all experiment groups $(p<0.05)$, however, P0 showed the largest decrement on redness and decreased steadily for whole storage period $(p<0.05)$. SánchezEscalante et al. (2001) reported that decrement of redness during storage was possibly due to oxidation of myoglobin (bright red) into metmyoglobin (brown), which may be related to lipid oxidation. AHE treated groups showed slightly higher values on yellowness ( $b *$-value) due to the color of AHE on the first $\mathrm{d}$ of measurement, however, there were no significant differences among all treatment groups $(p>0.05)$ and storage time also did not influence the yellowness $(p>0.05)$.

\section{AHE effects on conjugated dienes and TBARS value of pork patty}

Effects of AHE on the formation of $\mathrm{CD}$ during refrigerated storage are shown in Fig. 4. The concentration of CD is an index of the production of hydroperoxides at the early stage of lipid oxidation and these hydroperoxides are continuously decomposed to secondary products which can be measured by TBARS method as seen in this study (Peña-Ramos and Xiong, 2003). SP0 showed lower formation of $\mathrm{CD}$ compared to $\mathrm{P} 0$ until $7 \mathrm{~d}$ of storage $(p<0.05)$. Addition of AHE and ascorbic acid (SP1, SP2, and SP3) also affected the formation of $\mathrm{CD}$, resulting in significantly lower $(p<0.05)$ production of $\mathrm{CD}$ on patties than that of non-AHE added on $\mathrm{d} 7$ (P0 and SP0) and negative correlation between production of $\mathrm{CD}$ and $\mathrm{AHE}$ level was demonstrated $(\mathrm{r}=-0.805, p=0.01)$. This result was possibly caused by the antioxidant activity of AHE containing phenolic compounds and flavonoids. Lee et al. (2010) reported similar tendency of CD concentration in the raw ground pork meat treated with mustard leaf (Brassica juncea) kimchi extracts due to the antioxidant activity of the extract. The concentration of $\mathrm{CD}$ decreased rapidly after $7 \mathrm{~d}$ of storage which was observed in all experimental groups. Choe et al. (2011) suggested that decrement of $\mathrm{CD}$ concentration was due to the faster decomposition rate of $\mathrm{CD}$ into secondary products than the formation rate of $\mathrm{CD}$.

Table 1. Effects of Allium hookeri root extract (AHE) on color (CIE $L^{*}$-, $a^{*}$-, and $b^{*}$ - values) of raw sulfur-fed pork patties, and color of raw normal pork patties during $14 \mathrm{~d}$ of storage at $4^{\circ} \mathrm{C}^{1}$

\begin{tabular}{|c|c|c|c|c|c|c|}
\hline \multirow{2}{*}{ Parameters } & \multirow{2}{*}{$\begin{array}{l}\text { Storage periods } \\
\text { (d) }\end{array}$} & \multicolumn{5}{|c|}{ Treatments $^{2}$} \\
\hline & & P0 & SP0 & SP1 & SP2 & SP3 \\
\hline \multirow{4}{*}{$\mathrm{L}^{*}$-value } & 0 & $63.64 \pm 0.775^{\mathrm{Aa}}$ & $63.31 \pm 1.456^{\mathrm{Aa}}$ & $63.63 \pm 0.276^{\mathrm{Aa}}$ & $61.95 \pm 0.915^{\mathrm{Aa}}$ & $61.38 \pm 0.981^{\mathrm{Aa}}$ \\
\hline & 3 & $63.48 \pm 0.789^{\mathrm{Aa}}$ & $63.44 \pm 0.750^{\mathrm{Aa}}$ & $63.34 \pm 1.098^{\mathrm{Aa}}$ & $61.73 \pm 0.176^{\mathrm{Aa}}$ & $61.73 \pm 0.291^{\mathrm{Aa}}$ \\
\hline & 7 & $63.41 \pm 0.083^{\mathrm{ABa}}$ & $63.84 \pm 0.549^{\mathrm{Aa}}$ & $63.47 \pm 0.887^{\mathrm{Aa}}$ & $61.77 \pm 0.785^{\mathrm{BCa}}$ & $61.56 \pm 0.486^{\mathrm{Ca}}$ \\
\hline & 14 & $63.51 \pm 0.123^{\mathrm{Aa}}$ & $63.36 \pm 0.996^{\mathrm{Aa}}$ & $63.09 \pm 0.384^{\mathrm{ABa}}$ & $61.15 \pm 1.174^{\mathrm{Ba}}$ & $61.54 \pm 0.592^{\mathrm{ABa}}$ \\
\hline \multirow{4}{*}{$a^{*}$-value } & 0 & $9.05 \pm 0.104^{\mathrm{Ba}}$ & $9.70 \pm 0.388^{\mathrm{Aa}}$ & $5.91 \pm 0.235^{\mathrm{Ca}}$ & $4.34 \pm 0.201^{\mathrm{Da}}$ & $9.72 \pm 0.127^{\mathrm{Aa}}$ \\
\hline & 3 & $8.06 \pm 0.188^{\mathrm{Bb}}$ & $8.44 \pm 0.301^{\mathrm{ABb}}$ & $4.97 \pm 0.166^{\mathrm{Cb}}$ & $3.69 \pm 0.320^{\mathrm{Db}}$ & $8.84 \pm 0.197^{\mathrm{Ab}}$ \\
\hline & 7 & $7.38 \pm 0.413^{\mathrm{Cb}}$ & $8.15 \pm 0.226^{\mathrm{BCb}}$ & $3.42 \pm 0.110^{\mathrm{Dc}}$ & $3.46 \pm 0.267^{\mathrm{Db}}$ & $8.28 \pm 0.368^{\mathrm{Bb}}$ \\
\hline & 14 & $6.36 \pm 0.503^{\mathrm{Bc}}$ & $8.13 \pm 0.369^{\mathrm{Ab}}$ & $3.83 \pm 0.674^{\mathrm{Cc}}$ & $3.46 \pm 0.167^{\mathrm{Cb}}$ & $8.38 \pm 0.055^{\mathrm{Ab}}$ \\
\hline \multirow{4}{*}{$b^{*}$-value } & 0 & $13.03 \pm 0.291^{\mathrm{Aa}}$ & $13.52 \pm 0.217^{\mathrm{Aa}}$ & $13.69 \pm 0.571^{\mathrm{Aa}}$ & $13.94 \pm 0.594^{\mathrm{Aa}}$ & $13.24 \pm 0.093^{\mathrm{Aa}}$ \\
\hline & 3 & $13.01 \pm 0.243^{\mathrm{ABa}}$ & $13.10 \pm 0.356^{\mathrm{ABa}}$ & $13.54 \pm 0.393^{\mathrm{ABa}}$ & $13.90 \pm 0.477^{\mathrm{Aa}}$ & $12.82 \pm 0.467^{\mathrm{Ba}}$ \\
\hline & 7 & $12.95 \pm 0.425^{\mathrm{Aa}}$ & $13.12 \pm 0.564^{\mathrm{Aa}}$ & $13.80 \pm 0.924^{\mathrm{Aa}}$ & $14.28 \pm 0.899^{\mathrm{Aa}}$ & $13.01 \pm 0.448^{\mathrm{Aa}}$ \\
\hline & 14 & $13.06 \pm 0.240^{\mathrm{Aa}}$ & $13.57 \pm 0.546^{\mathrm{Aa}}$ & $13.72 \pm 0.459^{\mathrm{Aa}}$ & $13.77 \pm 0.190^{\mathrm{Aa}}$ & $13.06 \pm 0.311^{\mathrm{Aa}}$ \\
\hline
\end{tabular}

${ }^{1}$ Values are expressed as mean $\pm \mathrm{SD}$ of three replicates.

${ }^{2} \mathrm{P} 0$, normal pork patties; SP0, sulfur-fed pork patties; SP1, sulfur-fed pork patties with 1\% Allium hookeri root extract; SP2, sulfur-fed pork patties with $3 \%$ Allium hookeri root extract; SP3, sulfur-fed pork patties with $0.05 \%$ ascorbic acid.

${ }^{\text {A-D }}$ Means within a row with different letters differ significantly $(p<0.05)$.

${ }^{\mathrm{a}-\mathrm{c}}$ Means within a column with different letters differ significantly $(p<0.05)$. 


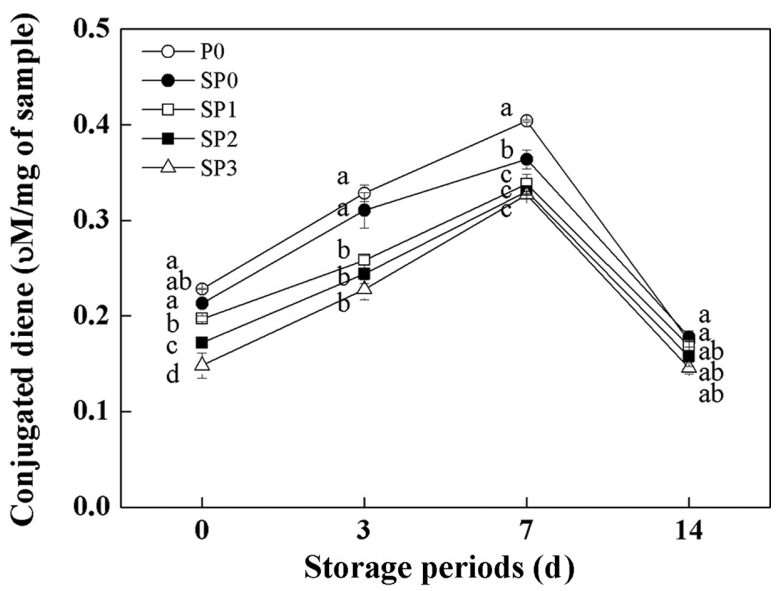

Fig. 4. Effects of Allium hookeri root extract (AHE) on the concentration of conjugated dienes $(C D, \mu M / \mathrm{mg}$ of sample) of raw sulfur-fed pork patties, and the concentration of CD of raw normal pork patties during $14 \mathrm{~d}$ of storage at $4^{\circ} \mathrm{C}$. Values are expressed as mean $\pm \mathrm{SD}$ of three replicates. P0, normal pork patties; SP0, sulfur-fed pork patties; SP1, sulfur-fed pork patties with $1 \%$ Allium hookeri root extract; SP2, sulfur-fed pork patties with $3 \%$ Allium hookeri root extract; SP3, sulfur-fed pork patties with $0.05 \%$ ascorbic acid. ${ }^{\mathrm{a}-\mathrm{d}} \mathrm{Means}$ with different letters on the same storage day are significantly different $(p<0.05)$.

The influences of AHE on TBARS values are presented in Fig. 5. The TBARS values were significantly affected $(p<0.05)$ by storage time and addition of AHE. On $\mathrm{d}$ 0 , TBARS values of all treatments were significantly lower than $\mathrm{P} 0(p<0.05)$, however, there were no significant differences except for P0 ( $p>0.05)$. The TBARS values increased until $7 \mathrm{~d}$ of storage. On $\mathrm{d} 7, \mathrm{P} 0$ showed the highest TBARS value than other treatment groups $(p<$ $0.05)$ and there were no significant differences among SP0, SP1, and SP2. SP3 showed the lowest TBARS value which was the positive control. P0 was more susceptible to lipid oxidation than SP0 until $7 \mathrm{~d}$ of storage. The result could suggest that sulfur-fed pork meat is more stable on lipid oxidation at least during primary storage of week. A study conducted by Lee et al. (2009) also reported similar profile of TBARS values during $8 \mathrm{~d}$ of chilled storage, suggesting that the raw meat of dietary methylsulfonylmethan (MSM) supplemented pigs were more resistant to lipid oxidation than that of non-MSM supplemented pigs. On $d 14$, TBARS values of all the treatment groups dramatically increased $(p<0.05)$. This result is in accordance with the changes in $\mathrm{CD}$ concentration in the present study. While CD hydroperoxides decreased being decomposed into secondary product of malondialdehyde, the TBARS values increased between 7 and $14 \mathrm{~d}$ of storage. Peña-

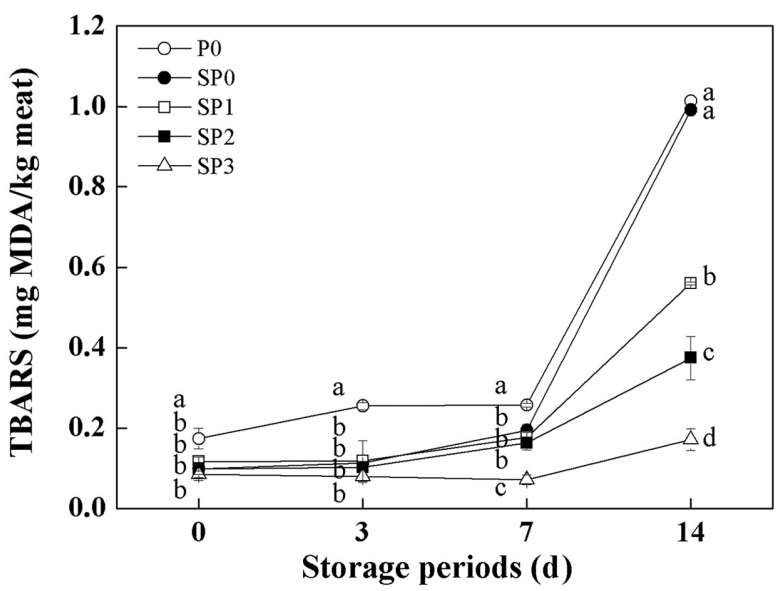

Fig. 5. Effects of Allium hookeri root extract (AHE) on thiobarbituric acid reactive substance (TBARS) values of raw sulfur-fed pork patties, and TBARS values of raw normal pork patties during $14 \mathrm{~d}$ of storage at $4^{\circ} \mathrm{C}$. Values are expressed as mean $\pm \mathrm{SD}$ of three replicates. P0, normal pork patties; SP0, sulfur-fed pork patties; SP1, sulfur-fed pork patties with $1 \%$ Allium hookeri root extract; SP2, sulfur-fed pork patties with 3\% Allium hookeri root extract; SP3, sulfur-fed pork patties with $0.05 \%$ ascorbic acid. ${ }^{\mathrm{a}-\mathrm{d}}$ Means with different letters on the same storage day are significantly different $(p<0.05)$.

Ramos and Xiong (2003) also stated similar results comparing $\mathrm{CD}$ and TBARS values in cooked pork patties during $7 \mathrm{~d}$ of chilled storage. On $\mathrm{d} 14, \mathrm{P} 0$ showed the highest TBARS value followed by SP0, however there was no significant difference between them $(p>0.05)$. SP2 showed a significantly lower TBARS value than SP1 $(p<0.05)$ and SP3 was the lowest one due to the antioxidant effect of ascorbic acid $(p<0.05)$. AHE effectively retarded the lipid oxidation in sulfur-fed pork patties which are proportion to the concentration of AHE against non-AHE treated patties as demonstrated by the negative correlation between TBARS and AHE level $(\mathrm{r}=-0.910, p=0.001)$.

The inhibitory effect of lipid oxidation on SP1 and SP2 may be related to high contents of phenolic compounds and flavonoids with excellent radical scavenging activity of water extracted AHE which is presented in this study (Fig. 1 and Fig. 2). Won et al. (2013) also evaluated antioxidant and anti-inflammatory components of Allium hookeri such as saponin, polypnehols, and flavonoids like quercetin. In addition, some sulfur containing compounds in Allium hookeri root characterized by high performance liquid chromatography-electrospray ionization-mass spectrometry were potent attributors on retardation of lipid oxidation of AHE added pork patties (Rhyu and Park, 2013). 


\section{Conclusions}

In this study, water extraction for $1 \mathrm{~h}$ was selected as an optimal condition to extract Allium hookeri root showing excellent recovery of phenolic compounds, flavonoids and antioxidant activity. AHE added into sulfur-fed pork patties effectively inhibited lipid oxidation rate during storage period due to its antioxidant activity. Thus, the results suggest that the potential usage of AHE as a natural preservative for its radical scavenging activity and positive effect on longer shelf life in food system.

\section{References}

1. Atmaca, G. (2004) Antioxidant effects of sulfur-containing amino acids. Yonsei Med J. 45, 776-788.

2. Ayam, V. S. (2011) Allium hookeri, Thw. Enum. A lesser known terrestrial perennial herb used as food and its ethnobotanical relevance in Manipur. Afr. J. Food Agric. Nutr. Dev. 11, 5389-5412.

3. Bae, G. C. and Bae, D. Y. (2012) The anti-inflammatory effects of ethanol extract of Allium hookeri cultivated in South Korea. Kor. J. Herbol. 27, 55-61.

4. Battin, E. E. and Brumaghim, J. L. (2009) Antioxidant activity of sulfur and selenium: a review of reactive oxygen species scavenging, glutathione peroxidase, and metal-binding antioxidant mechanisms. Cell Biochem. Biophys. 55, 1-23.

5. Choe, J. H., Jang, A., Lee, E. S., Choi, J. H., Choi, Y. S., Han, D. J., Kim, H. Y., Lee, M. A., Shim, S. Y., and Kim, C. J. (2011) Oxidative and color stability of cooked ground pork containing lotus leaf (Nelumbo nucifera) and barley leaf (Hordeum vulgare) powder during refrigerated storage. Meat Sci. 87, 12-18.

6. Choi, G. H. and Kim, C. H. (2002) Growth inhibition of extract from sulfur fed duck carcass against various cancer cell lines. Korean J. Food Sci. An. 22, 348-351.

7. Demirtas, I., Erenler, R., Elmastas, M., and Goktasoglu, A. (2013) Studies on the antioxidant potential of flavones of Allium vineale isolated from its water-soluble fraction. Food Chem. 136, 34-40.

8. Dziri, S., Hassen, I., Fatnassi, S., Mrabet, Y., Casabianca, H., Hanchi, B., and Hosni, K. (2012) Phenolic constituents, antioxidant and antimicrobial activities of rosy (Allium roseum var. odoratissimum). J. Funct. Food 4, 423-432.

9. Ellis, D. I. and Goodacre, R. (2001) Rapid and quantitative detection of the microbial spoilage of muscle foods: current status and future trends. Trends Food Sci. Technol. 12, 414424.

10. Hernández-Jover, T., Izquierdo-Pulido, M., Veciana-Nogués, M. T., and Vidal-Carou, M. C. (1996) Biogenic amine sources in cooked cured shoulder pork. J. Agr. Food Chem. 44, 3097-3101.

11. Jo, C., Son, J. H., Son, C. B., and Byun, M. W. (2003) Functional properties of raw and cooked pork patties with added irradiated, freeze-dried green tea leaf extract powder during storage at $4^{\circ}$ C. Meat Sci. 64, 13-17.

12. Jongberg, S., Skov, S. H., Tørngren, M. A., Skibsted, L. H., and Lund, M. N. (2011) Effect of white grape extract and modified atmosphere packaging on lipid and protein oxidation in chill stored beef patties. Food Chem. 128, 276-283.

13. Juntachote, T., Berghofer, E., Siebenhandl, S., and Bauer, F. (2006) The antioxidative properties of Holy basil and Galangal in cooked ground pork. Meat Sci. 72, 446-456.

14. Kanatt, S. R., Chander, R., and Sharma, A. (2007) Antioxidant potential of mint (Mentha spicata L.) in radiation-processed lamb meat. Food Chem. 100, 451-458.

15. Kaur, C. and Kapoor, H. C. (2002) Anti-oxidant activity and total phenolic content of some Asian vegetables. Int. J. Food Sci. Tech. 37, 153-161.

16. Kim, C. H., Lee, M. A., Kim, T. W., Jang, J. Y., and Kim, H. J. (2012) Anti-inflammatory effect of Allium hookeri root methanol extract in LPS-induced RAW264.7 cells. J. Korean Soc. Food Sci. Nutr. 41, 1645-1648.

17. Kim, L. S., Axelrod, L. J., Howard, P., Buratovich, N., and Waters, R. F. (2006) Efficacy of methylsulfonylmethane (MSM) in osteoarthritis pain of the knee: a pilot clinical trial. Osteoarthr. Cartilage. 14, 286-294.

18. Kyung, K. H. (2012) Antimicrobial properties of allium species. Curr. Opin. Chem. Biol. 23, 142-147.

19. Lee, J. I., Min, H. K., Lee, J. W., Jeong, J. D., Ha, Y. J., Kwack, S. C., and Park, J. S. (2009) Changes in the quality of loin from pigs supplemented with dietary methyl sulfonyl methane during cold storage. Korean J. Food Sci. An. 29, 229237.

20. Lee, M. A., Choi, J. H., Choi, Y. S., Han, D. J., Kim, H. Y., Shim, S. Y., Chung, H. K., and Kim, C. J. (2010) The antioxidative properties of mustard leaf (Brassica juncea) kimchi extracts on refrigerated raw ground pork meat against lipid oxidation. Meat Sci. 84, 498-504.

21. Leong, L. P. and Shui, G. (2002) An investigation of antioxidant capacity of fruits in Singapore markets. Food Chem. 76, 69-75.

22. McCarthy, T. L., Kerry, J. P., Kerry, J. F., Lynch, P. B., and Buckley, D. J. (2001) Evaluation of the antioxidant potential of natural food/plant extracts as compared with synthetic antioxidants and vitamin $\mathrm{E}$ in raw and cooked pork patties. Meat Sci. 58, 45-52.

23. Meda, A., Lamien, C. E., Romito, M., Millogo, J., and Nacoulma, O. G. (2005) Determination of the total phenolic, flavonoid and proline contents in Burkina Fasan honey, as well as their radical scavenging activity. Food Chem. 91, 571-577.

24. Mensor, L. L., Menezes, F. S., Leitão, G. G., Reis, A. S., Santos, T. C. D., Coube, C. S., and Leitão, S. G. (2001) Screening of Brazilian plant extracts for antioxidant activity by the use of DPPH free radical method. Phytother. Res. 15, 127-130.

25. Naczk, M. and Shahidi, F. (2006) Phenolics in cereals, fruits and vegetables: Occurrence, extraction and analysis. J. Pharm. Biomed. Anal. 41, 1523-1542.

26. Park, S. Y. and Chin, K. B. (2010) Effects of onion on physicochemical properties, lipid oxidation and microbial growth 
of fresh pork patties. Int. J. Food Sci. Tech. 45, 1153-1160.

27. Peña-Ramos, E. A. and Xiong, Y. L. (2003) Whey and soy protein hydrolysates inhibit lipid oxidation in cooked pork patties. Meat Sci. 64, 259-263.

28. Re, R., Pellegrini, N., Proteggente, A., Pannala, A., Yang, M., and Rice-Evans, C. (1999) Antioxidant activity applying an improved ABTS radical cation decolorization assay. Free Radical Bio. Med. 26, 1231-1237.

29. Rhyu, D. Y. and Park, S. H. (2013) Characterization of alkyl thiosulfinate in Allium hookeri root using HPLC-ESI-MS. $J$. Korean Soc. Appl. Biol. Chem. 56, 457-459.

30. Rice-Evans, C., Miller, N., and Paganga, G. (1997) Antioxidant properties of phenolic compounds. Trends Plant Sci. 2, 152-159.

31. Roy, M. K., Takenaka, M., and Isobe, S. (2007) Thermal processing enhances anti-radical activity and reduces pro-oxidant activity in water-soluble fraction of selected Allium vegetables. J. Sci. Food Agr. 87, 2259-2265.

32. Ryu, K. S., Shim, K. S., and Shin, D. K. (2014) ARTICLES: Effect of grape pomace powder addition on TBARS and color of cooked pork sausages during storage. Korean J. Food Sci. An. 34, 200-206.

33. Sánchez-Escalante, A., Djenane, D., Torrescano, G., Beltrán, J. A., and Roncalés, P. (2001) The effects of ascorbic acid, taurine, carnosine and rosemary powder on colour and lipid stability of beef patties packaged in modified atmosphere. Meat Sci. 58, 421-429.

34. Sharma, G., Gohil, R. N., and Kaul, V. (2011) Cytological status of Allium hookeri Thwaites $(2 \mathrm{n}=22)$. Genet. Resour. Crop Ev. 58, 1041-1050.

35. Singleton, V. L., Orthofer, R., and Lamuela-Raventos, R. M. (1999) Analysis of total phenols and other oxidation substrates and antioxidants by means of Folin-Ciocalteu reagent. Method Enzymol. 299, 152-178.

36. Sultana, B., Anwar, F., and Ashraf, M. (2009) Effect of extraction solvent/technique on the antioxidant activity of selected medicinal plant extracts. Molecules. 14, 2167-2180.

37. Thongtan, K., Toma, R. B., Reiboldt, W., and Daoud, A. Z. (2005) Effect of rosemary extract on lipid oxidation and sensory evaluation of frozen, precooked beef patties. Food Serv. Res. Int. 16, 93-104.

38. Witte, V. C., Krause, G. F., and Bailey, M. E. (1970) A new extraction method for determining 2-thiobarbituric acid values of pork and beef during storage. J. Food Sci. 35, 582585.

39. Won, J. Y., Yoo, Y. C., Kang, E. J., Yang, H., Kim, G. H., Seong, B. J., Kim, S. I., Han, S. H., Lee, S. S., and Lee, K. S. (2013) Chemical components, DPPH radical scavenging activity and inhibitory effects on nitric oxide production in Allium hookeri cultivated under open field and greenhouse conditions. J. Korean Soc. Food Sci. Nutr. 42, 1351-1356.

40. Wu, X., Beecher, G. R., Holden, J. M., Haytowitz, D. B., Gebhardt, S. E., and Prior, R. L. (2004) Lipophilic and hydrophilic antioxidant capacities of common foods in the United States. J. Agric. Food Chem. 52, 4026-4037. 